\title{
Expanded Technological Acceptance Model for the Sub-Saharan African Environment (ETAM-4SAE)
}

\author{
Martin Mabeifam Ujakpa and Delene Heukelman
}

\begin{abstract}
This research aimed at investigating the relationships between the Technological Adoption constructs (Perceived Usefulness, Perceived Ease of Use, Perceived Performance and Perceived Benefit) and variables in the Sub-Saharan African context and consequently develop an expanded TAM for the Sub-Saharan African environment, this study examined technology acceptance models, theories and framework to establish the concepts in them that apply in the environment. Applying a quantitative approach, the study collected data from 308 students (chosen at random) in five public universities (that were using e-learning systems) in five countries in the five regions of Sub-Sahara Africa. Performing multiple regression analysis, the probability (P) values (significance level) and standardized coefficients (prediction values, $\beta$ ) were computed. Based on the multiple regression correlation analysis, this study tested the technological adoption concepts in the Sub-Sahara African context and developed an expanded TAM for the Sub-Saharan African environment. Out of the four constructs of the developed expanded TAM, three (perceived ease of use, perceived usefulness and perceived performance) directly affect behavior intention which in turn directly affects technology adoption. Caution needs to be taken when applying this study's findings beyond the technology and population it considered as the technology and population it considered is not entire technologies used in Sub-Sahara Africa and entire population that use technologies in Sub-Sahara Africa. Further research on Technological Adoption may compare the developed TAM for the Sub-Saharan African environment to existing TAM by examining the variance of their constructs across defined periods and across cultures to determine their performance and hence explain different Technology Adoption behaviors in the Information Technology field. Applying the developed expanded TAM for technology adoption in the Sub-Saharan Africa environment is more likely to give accurate results than applying the existing TAM versions. The research developed an expanded TAM for technology adoption in the Sub-Saharan African environment. The developed model is useful as it came up with two new constructs (perceived performance and perceived benefit that is missing the original TAM).
\end{abstract}

Keywords-Technology Acceptance, Sub-Sahara Africa, Extended Technology Acceptance Model, Culture, E-learning

Manuscript received June10, 2020. M. M. Ujakpa is with Durban University of Technology, South Africa as a PhD Candidate and the International University of Management, Namibia as a Senior Lecturer and Faculty Dean. Previously he was with Ghana Technology University College, Accra Institute of Technology and Valley View University. D. Heukelman is the Research Coordinator for Faculty of Accountancy and Informatics at the Durban University of Technology, South Africa..

\section{INTRODUCTION}

The Technological Acceptance Model (TAM) is very relevant when examining and predicting technology acceptance. Recent studies that have used TAM include the study on "factors influencing consumer acceptance of Internet of Things (IOT) technology" [1], TAM - understanding academics' behavioral for learning management systems [2], "testing technology acceptance model 3 with the inclusion of change fatigue and overload" [3], "e-learning acceptance and assimilation" [4], "acceptance of human resource information system" [5] and "perceived interactivity, perceived ease of use and perceived usefulness of online hotel booking Intention" [6].

Applying TAM3 to investigate e-learning acceptance and assimilation, [4] concluded that TAM3 holds well in the Arabian culture. In consonance with [4] study, [5] study found that usage influenced the constructs Perceived Ease of Use (PEOU) \& Perceived Usefulness (PU) and the variables, information quality \& social influence respectively.

In their study on the constructs that influence consumer acceptance of Internet of Things (IoT), [1] applied the TAM to propose an IoT acceptance model. Apart from [1] integrated model providing more explanation on user Behavioral Intention (BI) toward IoT usage, they also found that trust (a third construct in their integrated model: social/cultural influence) played an insignificant role in predicting intention to accept. In their attempt to assist universities to predict the BI to use Learning Management Systems (LMS), [2] and [7] modified the TAM and UTAUT (Unified Theory of Acceptance and Use of Technology) models respectively using the core constructs PEOU, PU, and Attitude toward Usage (ATU). [2] [7] modification of TAM included external factors (LMS unavailability, prior LMS experience and job relevance).

Examining the dynamisms of variables that predict usage of LMS, [3] found substantial differences from links in the TAM3 model as the construct Subjective Norm and the variables, image, computer self-efficacy, computer anxiety, computer playfulness, perceived enjoyment, objective usability, and experience do not significantly impact the model. Using the findings of his work that, some variables fade in importance (as a result of greater fluency, more extensive use of computers, and effect of digital wisdom), [3] constructed a more parsimonious revised model of constructs and variables that reflected the said changes. Seemingly, to solve the complexity of using too many website interactive features as a way to improve the usefulness of websites, [8] reviewed past literature and based on TAM, proposed a conceptual framework with nine propositions to understand the role of Perceived Interactivity 
(PI), PEOU and PU towards website interactivity dimensions (two-way communication, responsiveness, and user control).

The above studies show the wide, continuous and global use of the original and modified TAM, based on defined environment/culture, to successfully predict Technology Adoption (TA) behavior in some international settings. Notwithstanding this, using the existing versions of TAM (1,2 and 3) within the Sub-Saharan African environment may not give best results [9]. Transfer of TAM concepts to different cultural environments (apart from the USA where it was developed) needs laborious testing. In their work, [9] indicated that, caution needs to be taken when applying TAM in some 20 identified countries as a result of cultural differences.

[10] and [11] points out additional limitations of the existing TAM versions. To [11], a deeper understanding of the concepts contributing to the constructs of PEOU and PU is needed; also, that further examination of different Information Systems (IS) and environments (cultural factors included) are neglected in the current versions of TAM. According to [10], the existing versions of TAM presume that technology is used at an individual level; hence organizational perspective is missing. Existing TAM also assumes that technology use is voluntary and hence use as a result of compulsion, is missing. Use by voluntary act or compulsion may be influenced by culture (which may vary from society to society).

As a result of TAM's limitation, [12] suggested that an expanded TAM be reflected as an obligatory part of any pre-implementation study of Information Communication Technology (ICT) among health workers in Sub-Saharan Africa. In consonance with [12] suggestion as above, [8] proposed a General Extended Technology Acceptance Model for e-Learning (GETAMEL) based on identified commonly used TAM external concepts in TA. Though [8] study was carried out in Africa, it did not focus on the African context; it rather focused on the most commonly used external concepts of TAM. Environmental factors (including cultural factors), were not considered in [8] GETAMEL; similarly system quality, information quality and service quality were not considered in developing GETAMEL [8].

Since [8] work did not focus on the African context, like the existing TAMs, GETAMEL's concepts may not hold true in the Sub-Saharan African context. In their quest to fill the above gap, [13] in their work on the theoretical underpinnings towards the acceptance of technological tools for supporting co-teaching, co-researching and co-learning for the Sub-Saharan African environment, came up with the concepts (constructs and variables) for TA in the African context. Based on discussions of the existing TAMs, theories, frameworks, their applications and analysis of quantitative data from e-learning users in five universities in five Sub-Saharan African countries, [13] recommended that, an expanded TAM in the Sub-Saharan African context be developed. This study therefore seeks to examine the relationship amongst TA constructs in the Sub-Saharan African context and develop the proposed expanded TAM for the Sub-Saharan African environment.

\section{LITERATURE REVIEW}

\section{Technology Acceptance Model (TAM)}

Propounded by [14] and as in Figure 1, the Technological Acceptance Model (TAM) has two main constructs ("Perceived Usefulness - PU) and Perceived Ease of Use (PEOU) which influence an individual's BI to using Information Technology (IT). Additionally, the model has three other constructs: Attitude towards Use (ATU), Intention to Use (IU) and Actual Usage (AU). PU and PEOU influence ATU and ATU influences IU and in turn, this influence Actual Usage. Data used in developing the model was collected in the USA and hence the resulting in a model influenced by USA/Western culture.

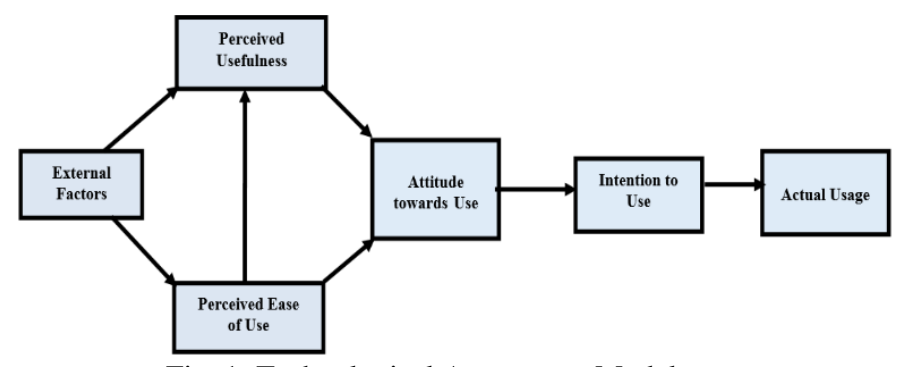

Fig. 1: Technological Acceptance Model

The original TAM, as in Figure 1, was found in very recent studies to still be an acceptable tool for predicting technological acceptance ([15] [16] [17] [18]. While [15] [16] [17] conducted research in Africa, the study conducted by [6] was conducted in the Netherlands.

In his studies, [15] found that insignificant relationships between Behavioral Intention (BI), PEOU and Social/Cultural Influence. [15] Finding that PEOU was insignificantly related to BI, contradicts [14] TAM model and hence a further study on [15] findings, especially within the Sub-Saharan African context, is needed. An earlier study on meta-analysis of the TAM provided sufficient data that credibly and strongly makes a case why PU and BI should be incorporated into the proposed EXPANDED model in the Sub-Saharan African context: Hence this study included PU and BI into the new expanded TAM.

In their study, [17] found that Behavioral Intention, user training and management support were major factors that determined actual usage of e-learning systems: thus, supporting the notion that knowledge/training and support are important variables to include in the proposed expanded model in the Sub-Saharan African context. Also [19] study found that; 1 . PU significant influenced BI to adopt the most, followed by lack of accessibility and performance to cost value. 2. Social environmental variables, tradition and social norms and lack of information about MOOCs were negatively associated with adoption of MOOCs and hence indicating the need to include PU and PP (accessibility and performance) as constructs in the expanded model.

\section{Newer Versions of TAM}

[20] Expanded TAM to create TAM2 as in Figure 2. The expansion was done by expanding the external variables that affect PU construct of TAM. The said external variables are categorised as: cognitive and social. The cognitive variable include "job relevance, output quality and result 
demonstrability". The social variable include "subjective norm and Image". The expanded TAM with these cognitive and social variable is referred to as TAM 2.

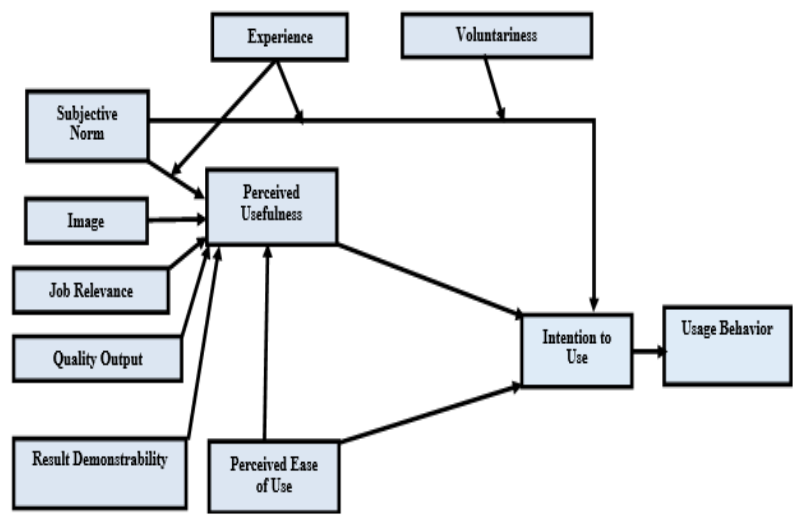

Fig. 2: Technological Acceptance Model 2

Combining variables of Perceived Ease of Use" and TAM 2, [21] developed TAM3 as shown in Figure 3.

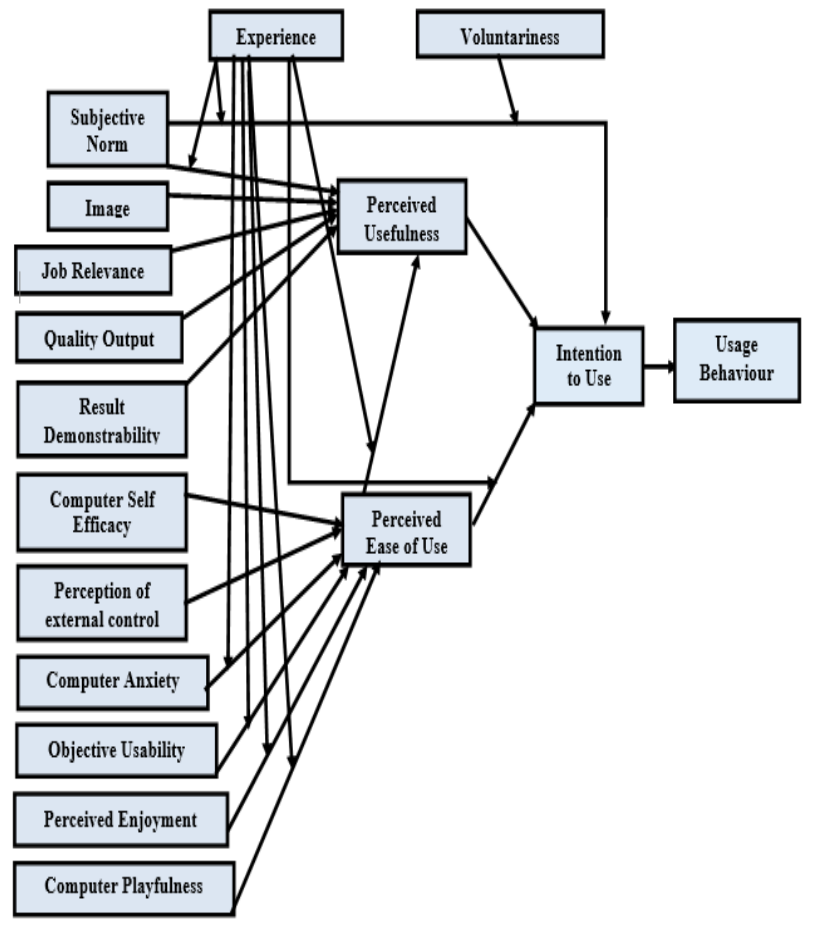

Fig. 3: Technological Acceptance Model 3

Apart from the use of the original TAM in previous studies [15] [16] [17] [18] as discussed above, the modified or expanded TAMs were also used by other previous studies. These studies include the studies of [22] [23].

Applying a modified TAM as in Figure 4, [22] found that Perceived Enjoyment was the most influential on BI, followed by PU, and PEOU.

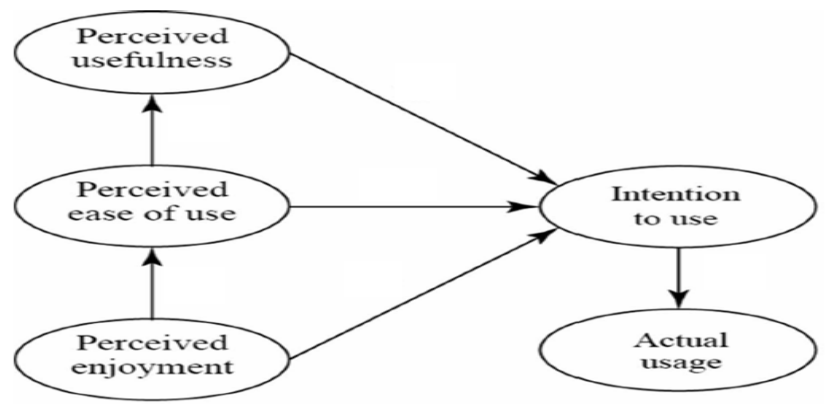

Fig. 4: Modified TAM

In her study, [23], identified seven concepts that influenced users' intention to use a Hospital Information System (HIS): Subjective Norm (SN), PU, PEOU, User Satisfaction (US), BI, Attitude towards Usage and Actual System Usage. Since the study by [23] was conducted in a developing country, the seven identified constructs were considered for the proposed expanded TAM in the Sub-Saharan African context. SN is going to be examined through two variables (influence by peers and influence by important persons) in this research. Seemingly, [24] study on factors determining students' video usage and their learning satisfaction, found that, 1. "Perceived Usefulness, Attitude, and Internet Self-Efficacy had a direct effect on the video usage", 3. Learner-Learner Interaction, PEOU, and Learning Performance directly influenced Learning Satisfaction. Considering that the attitude and learner-learner interaction are more likely to stems' from culture which may influence frequency of use, experience and internet self-efficacy, this study included culture, frequency of use and experience as variables in the expanded model.

Furthermore, [25] also found that user willingness to use and knowledge management influenced technology adoption. Since user willingness to use and knowledge management match frequency of use and experience respectively, [25] findings give further reasons why frequency of use and experience should be included as variables in the proposed expanded TAM model in the Sub-Saharan African context.

The constructs identified in studies, using the existing and modified TAM's, which were suitable for the expanded TAM for an Sub-Saharan African context were therefore PEOU, PU, $\mathrm{PP}, \mathrm{BI}, \mathrm{TA}$. The variables influencing the constructs are culture, frequency of use and experience, influence by peers and influence by important persons, accessibility and performance

\section{Information System Success Model (ISSM)}

As in Figure 5 and as propounded by [26], the ISSM has six concepts: "system quality, information quality, use, user satisfaction, individual impact, and organizational impact". Using these concepts, [26], created the Information System Success Model (ISSM). Figure 4 depicts the ISSM Model. 


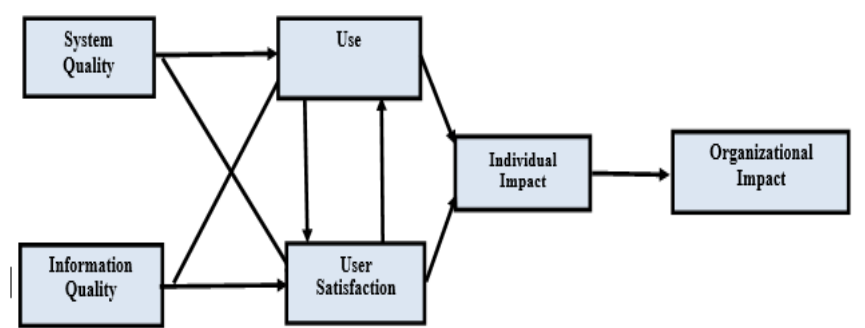

Fig. 5: Information System Success Model

Based on other researchers' suggestion for additional modifications, [27] modified the 'use' variable in the original ISSM into two: "intention to use and use" and also added service quality to the ISSM. The modified ISSM as in Figure 6, is referred to as "updated information system success model.

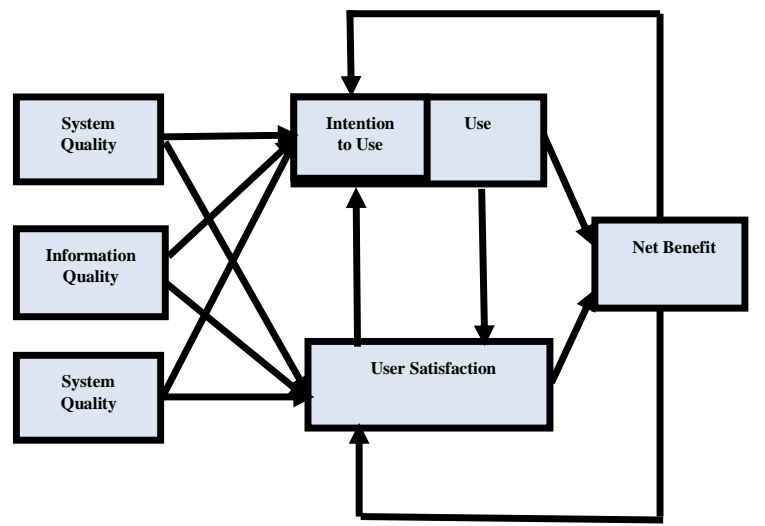

Fig. 6: Updated Information System Success Model

Studies that have made use of the ISSM models include [27] study to measure Information Systems Success that found that "progress in measuring individual success dimensions has been slow, and valid and reliable measures have yet to be developed and consistently applied for system quality, information quality, use, and net benefits" [27]. These results indicate the quest for the development of technological concepts in the context of the environment in which it used/will be to measure technological adoption.

\section{Technology Organisation and Environment (TOE) Framework}

As in Figure 7 and developed by [28], recent studies that have found it as a technological acceptance predicting tool include the studies of [29] [30] [19]. While [29] recommended further study on TOE framework to include some further concepts, [30] used of it in developing a technological adoption model; hence indicating the possibility of using some of its concepts (especially the environment dimension - cultural related) in the proposed TAM in the Sub-Saharan African context.

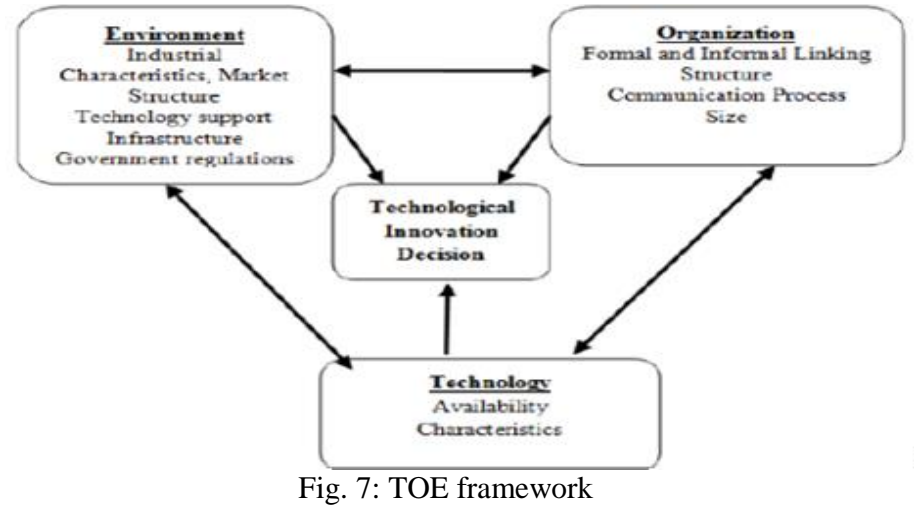

The discussion above, suggest the need for TAM in the context in which it is used. To achieve this, some previous studies expanded the existing TAM. Considering the Sub-Saharan African culture, there is the need for a TAM in the Sub-Saharan African context. Hence this study developed an expanded TAM in the Sub-Saharan African Context.

\section{Research Hypothesis}

Based on literature reviewed above, the conclusion and recommendation of [13] that $\mathrm{BI}$ is influenced by four main constructs (PU, PEOU, PP and PB) in the Sub-Saharan African context and that associated relationship between these constructs should be examined further; the following expanded TAM model was proposed in the Sub-Saharan African context:

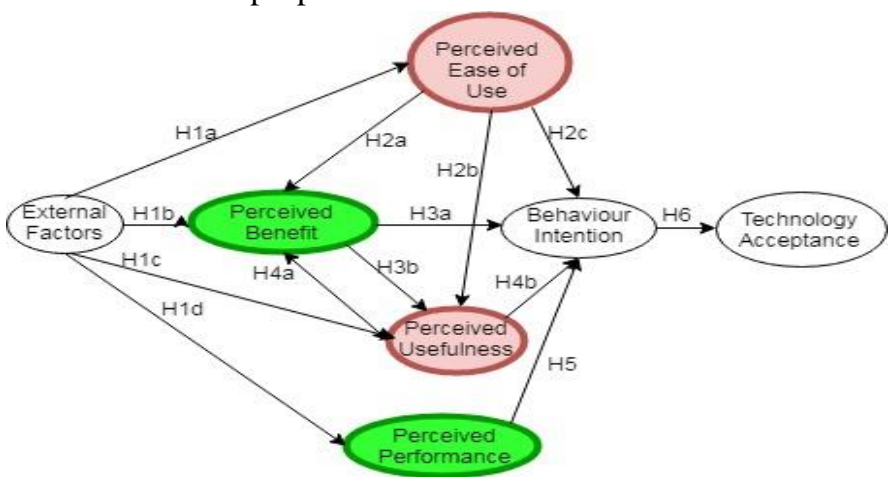

Fig. 9: Relationship in the expanded TAM model in the Sub-Saharan African context

Based on the proposed TAM model in Figure 9, the following hypotheses were proposed:

1. H1a: External Factors (EF) influence Perceived Ease of Use of Technology (PEOU)

2. H1b: External Factors influence Perceived Benefit of using Technology (PB)

3. H1c: External Factors (EF) influence Perceived Usefulness of Technology (PU)

4. H1d: External Factors (EF) influence Perceived Performance of Technology (PP)

5. H2a: Perceived Ease of Use (PEOU) of Technology influences Perceived Benefit (PB) of using technology

6. H2b: Perceived Ease of Use (PEOU) of Technology influences Perceived Usefulness (PU) to use Technology

7. H2c: Perceived Ease of Use (PEOU) of Technology influences Behavioural Intention (BI) to use technology 
TABLE III: P VALUES AND B VALUES

\begin{tabular}{|c|c|c|c|c|c|c|c|}
\hline \multirow{2}{*}{$\begin{array}{c}\text { No } \\
1 .\end{array}$} & \multirow{2}{*}{$\begin{array}{c}\text { Hypothesis } \\
\text { H1a }\end{array}$} & \multicolumn{3}{|c|}{ Path } & \multirow{2}{*}{$\begin{array}{c}\begin{array}{c}\text { Standard } \\
\text { Coefficient } \\
\text { (B) }\end{array} \\
0.146\end{array}$} & \multirow{2}{*}{$\begin{array}{c}\text { Probability } \\
\text { Value } \mathbf{P}(\mathbf{P} \\
\leq \mathbf{0 . 0 5}) \\
0.010\end{array}$} & \multirow{2}{*}{$\begin{array}{c}\text { Hypothesis } \\
\text { Results } \\
\text { Based on P- } \\
\text { Value } \\
\text { Accepted }\end{array}$} \\
\hline & & EF & & PEOU & & & \\
\hline 2. & H1b & $\mathrm{EF}$ & & B & 0.235 & 0.001 & Accepted \\
\hline 3. & H1c & $\mathrm{EF}$ & & PU & 0.113 & 0.047 & Accepted \\
\hline 4. & H1d & $\mathrm{EF}$ & & PP & 0.131 & 0.021 & Accepted \\
\hline 5. & $\mathrm{H} 2 \mathrm{a}$ & PEOU & & B & 0.190 & 0.001 & Accepted \\
\hline 6. & $\mathrm{H} 2 \mathrm{~b}$ & PEOU & & PU & 0.932 & 0.001 & Accepted \\
\hline 7. & $\mathrm{H} 2 \mathrm{c}$ & PEOU & & $\mathrm{BI}$ & 0.190 & 0.001 & Accepted \\
\hline 8. & $\mathrm{H} 3 \mathrm{a}$ & B & & $\mathrm{BI}$ & 0.015 & 0.790 & Rejected \\
\hline 9. & $\mathrm{H} 3 \mathrm{~b}$ & B & & PU & 0.411 & 0.001 & Accepted \\
\hline 10. & $\mathrm{H} 4 \mathrm{a}$ & PU & - & B & 0.202 & 0.001 & Accepted \\
\hline 11. & $\mathrm{H} 4 \mathrm{~b}$ & PU & & $\mathrm{BI}$ & 0.202 & 0.001 & Accepted \\
\hline 12. & H5 & PP & - & $\mathrm{BI}$ & 0.131 & 0.021 & Accepted \\
\hline 13. & H6 & $\mathrm{BI}$ & 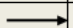 & TA & 0.113 & 0.047 & Accepted \\
\hline
\end{tabular}

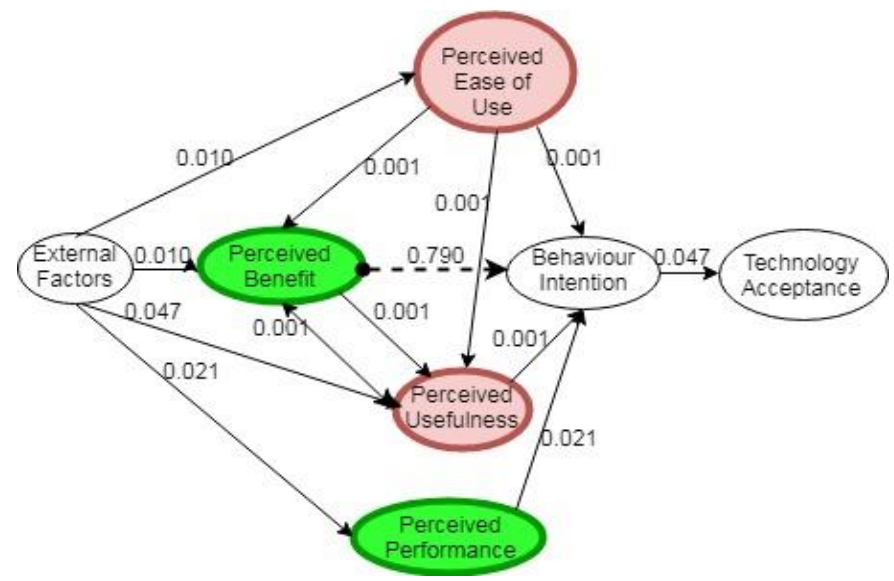

Fig. 10: Developed expanded TAM in the Sub-Saharan African Context

Results in Figure 10 and Table 3 confirm that three factors (PU, PEOU and PP) positively influence BI directly. Among these three factors, $\mathrm{PU}(\mathrm{H} 4 \mathrm{~b})$ was the strongest determinant of Behavior Intention $(\beta=0.202, P$ value $\leq 0.001)$, followed by Perceived Ease of Use $(\mathrm{H} 2 \mathrm{c})(\beta=0.190, \mathrm{P}$ value $\leq 0.001)$ and Perceived Performance (H5) $(\beta=0.131, \mathrm{P}$ value $\leq 0.021)$. This result confirms that TAM's constructs, PU and PEOU, were functional and significant in predicting Behavioral Intention (BI) towards Technological Adoption in the Sub-Saharan African context.

In the developed expanded model in the Sub-Saharan African context, PEOU, Perceived Benefit (PB) and External factors were hypothesized to influence PU, positively. The three hypotheses were accepted with PEOU (H2b) being the strongest determinant of $\mathrm{PU}(\beta=0.932$, $\mathrm{P}$ value $\leq 0.001)$, followed by $\mathrm{PB}$ $(\beta=0.411, \mathrm{P}$ value $\leq 0.001)$ and External factors $(\beta=0.113, \mathrm{P}$ value $\leq$ 0.047). External Factors, PU and PEOU were hypothesized as positively influencing PB. Among these three, External Factors ( $\mathrm{H} 1 \mathrm{~b})$ was the strongest determinant of $\mathrm{PB}(\beta$ $=0.235, \mathrm{P}$ value $\leq 0.001)$, followed by $\mathrm{PU}(\beta=0.202, \mathrm{P}$ value $\leq$ $0.001)$ and PEOU $(\beta=0.190, \mathrm{P}$ value $\leq 0.001)$.
In the developed model, External Factors positively influence Perceived Performance (PP), PEOU, PU and PB. Among the three, External factors positively influenced $\mathrm{PB}(\mathrm{H} 1 \mathrm{~b})$ the most $(\beta=0.235, \mathrm{P}$ value $\leq 0.001)$ the most, followed by PEOU (H1a) ( $\beta=0.146$, $\mathrm{P}$ value $\leq 0.010)$, PP $(\mathrm{H} 1 \mathrm{~d})(\beta=0.131$, $\mathrm{P}$ value $\leq$ $0.021)$ and $\mathrm{PU}(\beta=0.113, \mathrm{P}$ value $\leq 0.047)$. Finally, Figure 9 also illustrates that BI (H6) positively influence TA $(\beta=0.113$, $\mathrm{P}$ value $\leq 0.047)$ and that $\mathrm{PB}(\mathrm{H} 3 \mathrm{a})$ does not influence $\mathrm{BI}(\beta$ $=0.015, \mathrm{P}$ value $\leq 0.790$ ).

\section{CONCLUSION AND RECOMMENDATION}

The research aimed to develop and evaluate an expanded Technological Acceptance Model (TAM) that can be utilized to evaluate technology adoption in the Sub-Saharan African Environment. As part of this research, the existing TAM, ISSM and UTAUT concepts (constructs) relevant to the Sub-Saharan African environment as identified in [13] study were applied to develop the expanded TAM in the Sub-Saharan African context. From the quantitative data analysis, the construct PU was the strongest determinant of BI. This was due to output of the technology at the respondents' institutions being complete, concise, current, timely and comprehensible, thus good information quality. The technology also have working functionalities, which make it useful to students and thereby positively affecting their productivity and performance. This resulted in students' satisfaction with the system and hence encouraging them to use it frequently and voluntarily in the absence of a force-use policy.

Results from the quantitative data analyses of this research also indicate that PEOU was the second strongest determinant of BI. This is because the technology in the respondents' institutions was reliable, flexible, simple, fast, pleasant and comfortable to use and easily navigable, had all expected functionalities, gave clear error messages and how to fix the errors, allowed users to easily recover from mistakes and overall required little mental efforts from the user to use: thus good system quality. This is also because, respondents either had an experience of using the technology prior to joining their institution or they received training on the technology usage in their institutions. The results also confirmed that technology was easy to access, easy to learn and easy to use, thereby requiring less mental efforts to use. It even became much easier as students encouraged each other to use the technology. Lecturers also encouraged students to use the technology and hence a confirmation previous findings on TAM [14] [21]. The direct relationship between PEOU and BI to the intention to use, is documented by several studies [32] [33] [34] [35] [36] [11] [28] [8] [37].

The results of the study also showed that PP was the third strongest determinant of BI. This could also be linked to the high quality of the technology from respondents' institutions. The high system quality is as a result of the respondents' Institution Information Technology staff being available, responding to queries on time, having empathy for e-learning users, being reliable and technically competent, providing accurate solutions and documented guidance (in the form of manuals: manual / digital) on technology use: thus high system services quality as well as a third construct, PP, in addition to the two existing constructs [14] [21], was therefore established 
by this study. PP is thus a new construct, and although it may not be limited to the Sub-Saharan African environment, it may have more influence within the Sub-Saharan African context where resources may be very limited, than in other environments less adverse to risk and with more resources.

The study results indicate that system quality is an important variable to the PEOU construct. This implies that, stakeholders in the design, development or implementation of a technology, should ensure that it is reliable, flexible, simple, fast, pleasant, comfortable to use and navigate. They should also ensure that the technology has expected functionalities, gives error messages with clear messages on how to fix the errors, allow users to easily recover from mistakes and overall require little mental efforts from user to use. Additionally, training, user manuals availability, experience of a technology and user centeredness directly influence Perceived Ease of Use. This denotes that adoption of a technology is highly dependent on whether users have received training on the technology and whether user manuals are available and easily accessible. It also infers that user experience and user centeredness of the technology determine the technology adoption, hence designers should design technologies such that it is user centered, comes with user manuals accessible in all possible formats and that technology implementers ensure that users receive training on it.

The study results also indicate that peer and important personnel directly influence subjective norm and the three together directly influence Perceived Benefit. This signifies that when colleagues of a category of persons or important personnel to a category of persons use and encourage the use of a technology, its acceptance is high. A group of influential individuals from different levels within the organization could play a vital role in the successful implementation of new technology. For instance, in the case of this study, students tend to use e-learning based on colleagues and lecturers influence. Furthermore, the study results indicate that information quality is a significant variable influencing the PU construct. This signifies that, stakeholders in designing, developing or implementing a technology, should ensure that the information output of the technology is complete, concise, current, timely and comprehensible.

Additionally, the frequency of use, voluntariness in use, the culture of independence or group acceptance or general use or compulsion of use and uncertainty avoidance directly influence PU. This implies that a technology becomes more acceptable in the context of the Sub-Saharan Africa environment as one tends to use it voluntarily and/ or more. Equally the Technology tends to be acceptable when found in a culture where group acceptance is high and also when some group members use the technology and tend to approve of other group members that also use the technology. Based on the above, cultures like work environments should encourage the voluntary use as technology as its group members' actions and benefit from the system will encourage others to use it.

The study also found that PEOU and PB directly influence PU which in turn influence Perceived Benefit. This denotes that technology be designed such that it's easy to use as this will influence users' BI towards use. Service quality is a significant variable influencing the PP construct. This implies that, stakeholders in the implementation of a technology, should ensure that information technology services support staff are available, reliable, competent, have empathy and provide accurate solutions to staff as these influence users perception of PP and TA. PEOU, PU and PP directly affect BI which directly affects TA. This denotes that, for a technology to be accepted in the Sub-Saharan African environment, it should be perceived to be easy to use, useful, and beneficial and to have a high performance.

Though this research was able to reach some stimulating findings and developed an expanded TAM for the Sub-Saharan African environment, it has some limitations. Firstly the research technology (e-learning) and population (universities in Sub-Saharan Africa) does not cover the entire technologies and population in Sub-Saharan Africa, respectively. Secondly, the research sample was limited to students in public universities: however users of technology in universities go beyond students to include lecturers, administrative staff and the general public. As a result, caution needs to be taken when generalizing this research findings beyond the said population and technology. Further research on TA may compare the developed expanded TAM for the Sub-Saharan African environment to existing TAM by examining the variance of their constructs across defined periods and across cultures to determine their performance and hence explain different TA behaviors in the Information Technology field. Based on this, future research could extend the developed expanded model to explain the variance in students' BI based on PU, PEOU, PP, and PB.

\section{REFERENCE}

[1] Gao, L. and Bai X. (2014). A Unified Perspective on the Factors Influencing Consumer Acceptance of Internet of Things Technology. Asia Pacific Journal of Marketing and Logistics, 26(2), Pp.211-231. https://doi.org/10.1108/APJML-06-2013-0061

[2] Alharbi S. and Drew S. (2014). Using the Technology Acceptance Model in Understanding Academics' Behavioural Intention to Use Learning Management Systems. International Journal of Advanced Computer Science and Applications, 5(1). https://doi.org/10.14569/IJACSA.2014.050120

[3] Jeffrey A. D. (2015). Testing the Technology Acceptance Model 3 with the Inclusion of Change Fatigue and Overload, in the Context of Faculty from Seventh Day Adventist Universities: A Revised Model. Andrews University

[4] Al-Gahtani S. S. (2016). Empirical Investigation of E-Learning Acceptance and Assimilation: A Structural Equation Model. Applied Computing and Informatics, 12, Pp.27-50 https://doi.org/10.1016/j.aci.2014.09.001

[5] Kamaludin, K., and Kamaludin, K., Z. (2017). User Acceptance of the Human Resource Information System: A Study of a Private Hospital in Malaysia. International Review of Management and Marketing, 7(2), Pp.207-217.

[6] Abdullah D., Jayaraman K., Shariff N. D., Bahari A. K. and Nor Md. N. (2017). The Effects of Perceived Interactivity, Perceived Ease of Use and Perceived Usefulness on Online Hotel Booking Intention: A Conceptual Framework. International Academic Research Journal of Social Science 3(1), Pp.16-23

[7] Chao C. (2019). Factors Determing Behavuor Intention to Use Mobile Learning: An application and Extention of the UTAUT Model. Psychol. https://doi.org/10.3389/fpsyg.2019.01652

[8] Abdullah, F. and Ward, R. (2016). Developing a General Extended Technology Acceptance Model for E-Learning (GETAMEL) by analysing commonly used external factors. Computers in Human Behavior, 56, Pp.238-256. https://doi.org/10.1016/j.chb.2015.11.036

[9] McCoy, S., Galletta, D., F., and King, W., R. (2007). Applying TAM across Cultures: The Need for Caution. European Journal of Information System, 16(1), Pp.81-90.

https://doi.org/10.1057/palgrave.ejis.3000659 
[10] Woraporn, R., and Seung, K. (2002). A Framework to Study Technology Use: Alternatives to Technology Acceptance Model. Americas Conference on Information Systems, Proceedings 127, Pp.883-889. Retrieved from:

http://aisel.aisnet.org/amcis2002/127

[11] Lee, Y., Kozar, K., A., and Larsen, K., R., T. (2003). The Technology Acceptance Model: Past, Present, and Future. Communications of the Association for Information Systems, 12 (50), Pp.752-780. https://doi.org/10.17705/1CAIS.01250

[12] Jimoh, L., Pate, M., A., Lin, L., and Schulman, K., A. (2012). A Model for the Adoption of ICT by Health Workers in Africa. Int J Med Inform. $81(11)$ https://doi.org/10.1016/j.ijmedinf.2012.08.005

[13] Ujakpa, M. M. and Heukelman, D. (2020). Proposed Expanded TAM in the Sub-Saharan African Context: Theoretical Underpinnings towards the Acceptance of Technological Tools for supporting Co-Teaching, Co-Researching and Co-Learning. Manuscript submitted for publication (Digital Literacy and Socio-Cultural Acceptance of ICT in Developing Countries).

[14] Davis, F., D., and Venkatesh, V. (2004). Toward Pre-prototype User Acceptance Testing of New Information Systems: Implications for Software Project Management. IEEE Transactions on Engineering Management, 51(1), Pp.31-46.

https://doi.org/10.1109/TEM.2003.822468

[15] Ibrahim T. A. (2018), "The Role of Technology Acceptance Model in Explaining University Academics' Acceptance and Behavioural Intention to Use Technology in Education". 4th International Research Conference on Higher Education, KnE Social Sciences, Pp 1162-1172. https://doi.org/10.18502/kss.v3i6.2443

[16] Matikiti, R., Mpinganjira, M. and Roberts-Lombard, M., (2018), 'Application of the Technology Acceptance Model and the TechnologyOrganisation-Environment Model to examine social media marketing use in the South African tourism industry', South African. Journal of Information Management, 20(1) https://doi.org/10.4102/sajim.v20i1.790

[17] Ayele A. A., and Birhanie W. K. (2018). Acceptance and Use of E-learning Systems: the case of Teachers in Technology Institutes of Ethiopian Universities. Appl Inform, 5(1), Pp1-11. https://doi.org/10.1186/s40535-018-0048-7

[18] Brandon-Jones, A. and Kauppi, K. (2018). Examining the antecedents of the Technology Acceptance Model within E-procurement. International Journal of Operations and Production Management, 38(1), Pp22 - 42 https://doi.org/10.1108/IJOPM-06-2015-0346

[19] Ma L. and Lee S. C. (2018). Investigating the Adoption of MOOCs: A Technology-User-Environment Perspective. Journal of Computer Assisted Learning, 35:89-98 https://doi.org/10.1111/jcal.12314

[20] Venkatesh V and Davis F. (2000). Determinants of Perceived Ease of Use: Integrating Control, Intrinsic Motivation, and Emotion into the Technology Acceptance Model. University of Maryland, Maryland, USA. https://doi.org/10.1287/isre.11.4.342.11872

[21] Venkatesh, V., and Bala, H. (2008). Technology Acceptance Model 3 and a Research Agenda on Interventions. Decision sciences, 39(2), Pp.273-315. https://doi.org/10.1111/j.1540-5915.2008.00192.x

[22] Byun H., Chiu W, Bae J. (2018). Exploring the Adoption of Sports Brand Apps: An Application of the Modified Technology Acceptance Model. International Journal of Asian Business and Information Management, 9(1). Pp $52-65$ https://doi.org/10.4018/IJABIM.2018010105

[23] Helia V. N., Asri V. I, Kusrini E., and Miranda S. (2018). Modified Technology Acceptance Model For Hospital Information System Evaluation - A Case Study. MATEC Web of Conferences, 154. https://doi.org/10.1051/matecconf/201815401101

[24] Nagy J. T. (2018). Evaluation of Online Video Usage and Learning Satisfaction: An Extension of the Technology Acceptance Model. International Review of Research in Open and Distributed Learning, 19(1). https://doi.org/10.19173/irrodl.v19i1.2886

[25] Siregar J. J., Puspokusumo A. W. R.A. and Rahayu A. (2017). Analysis of Affecting Factors Technology Acceptance Model in the Application of Knowledge Management for Small Medium Enterprises in Industry Creative. 2nd International Conference on Computer Science and Computational Intelligence, Bali, Indonesia https://doi.org/10.1016/j.procs.2017.10.075
[26] Delone W. H and Mclean E. R. (2004) Measuring e-commerce success: reapplying the DeLone and McLean information systems success model. International Journal of Electronic Commerce, 9(1), 31-47 https://doi.org/10.1080/10864415.2004.11044317

[27] Petter S., DeLone W. and McLean E. (2008). Measuring Information Systems Success: Models, Dimensions, Measures and Interrelationships. European Journal of Information Systems, 17, Pp.236-263. https://doi.org/10.1057/ejis.2008.15

[28] Tornatzky, L. G. and Fleischer M. (1990). Process of Technological Innovation. Lexington Books. USA, Massachusetts/Toronto.

[29] Kilström T. (2016). Factors limiting Adoption of new Technology: a Study of Drawbacks affecting Transition from On-premise Systems to Cloud Computing. KTH Industrial Engineering and Management.

[30] Ismail N. S. W. W. and Azwadi A. A. (2016). Conceptual Model for Examining the Factors that influence the likelihood of Computerised Accounting Information System (CAIS) Adoption among Malaysian SMEs. International Journal of Information Technology and Business Management, 15(1): 122 - 151

[31] Zealousys. (2017). E-Learning Trends in Africa. Zealous Systems. Retrieved from: http://www.zealousys.com/blog/e-learning-trends-africa-2017/

[32] Nikou A. S. and Economides A. A. (2019). Factors that influence behavioral intention to use mobile-based assessment: A STEM teachers' perspective. British Journal of Educational Technology, 50(2). https://doi.org/10.1111/bjet.12609

[33] Jaiyeoba O. O., Iloanya J. (2019) "E-learning in tertiary institutions in Botswana: apathy to adoption", The International Journal of Information and Learning Technology, Vol. 36 Issue: 2, pp.157-168, https://doi.org/10.1108/IJILT-05-2018-0058

[34] Chen X., Tao D. and Zhou Z. (2019). Factors Affecting Reposting Behaviour using a Mobile Phone-based User-Generated-content Online Community Application among Chinese Young Adults. Behaviour and Information Technology, 38(2), Pp 120-131. https://doi.org/10.1080/0144929X.2018.1515985

[35] Chuchu T and Ndoro T. (2019). An Examination of the Determinants of the Adoption of Mobile Applications as Learning Tools for Higher Education Students. International Journal of Interactive Mobile Technologies, 13(3). https://doi.org/10.3991/ijim.v13i03.10195

[36] Portz J. D. et al (2019). Using the Technology Acceptance Model to Explore User Experience, Intent to Use, and Use Behavior of a Patient Portal among Older Adults with Multiple Chronic Conditions: Descriptive Qualitative Study. J Med Internet Res, 21(4). https://doi.org/10.2196/11604

[37] Hamida A. A., Razak A. Z. F., Bakar A. A. and Abdullah W. S. W. (2016). The Effects of Perceived Usefulness and Perceived Ease of Use on Continuance Intention to Use E-Government. Procedia Economics and Finance, 35, Pp. 644-649 https://doi.org/10.1016/S2212-5671(16)00079-4 